\title{
Acute Stress Induces Selective Alterations in Cost/Benefit Decision-Making
}

\author{
Naghmeh Shafiei ${ }^{1,2}$, Megan Gray, ${ }^{2,3}$, Victor Viau, ${ }^{2,3}$ and Stan B Floresco*,1,2 \\ 'Department of Psychology, University of British Columbia, Vancouver, BC, Canada; ${ }^{2}$ Brain Research Center, University of British Columbia, \\ Vancouver, BC, Canada; ${ }^{3}$ Department of Cellular and Physiological Sciences, University of British Columbia, Vancouver, BC, Canada
}

\begin{abstract}
Acute stress can exert beneficial or detrimental effects on different forms of cognition. In the present study, we assessed the effects of acute restraint stress on different forms of cost/benefit decision-making, and some of the hormonal and neurochemical mechanisms that may underlie these effects. Effort-based decision-making was assessed where rats chose between a low effort/reward $(\mathrm{I}$ press $=2$ pellets) or high effort/reward option (4 pellets), with the effort requirement increasing over 4 blocks of trials (2, 5, I0, and 20 lever presses). Restraint stress for I h decreased preference for the more costly reward and induced longer choice latencies. Control experiments revealed that the effects on decision-making were not mediated by general reductions in motivation or preference for larger rewards. In contrast, acute stress did not affect delay-discounting, when rats chose between a small/immediate vs larger/delayed reward. The effects of stress on decision-making were not mimicked by treatment with physiological doses of corticosterone (I-3 mg/kg). Blockade of dopamine receptors with flupenthixol $(0.25 \mathrm{mg} / \mathrm{kg})$ before restraint did not attenuate stress-induced effects on effort-related choice, but abolished effects on choice latencies. These data suggest that acute stress interferes somewhat selectively with cost/benefit evaluations concerning effort costs. These effects do not appear to be mediated solely by enhanced glucocorticoid activity, whereas dopaminergic activation may contribute to increased deliberation times induced by stress. These findings may provide insight into impairments in decision-making and anergia associated with stress-related disorders, such as depression.

Neuropsychopharmacology (2012) 37, 2194-2209; doi: 10.1038/npp.2012.69; published online 9 May 2012
\end{abstract}

Keywords: restraint stress; effort-based decision-making; delay-discounting; corticosterone; dopamine; rats

\section{INTRODUCTION}

Substantial evidence suggests that acute stress alters different forms of cognitive functioning, in a manner dependent on a variety of factors, including the type of task, the specific brain circuitry recruited by these tasks, and the severity of the stressor (Shors et al, 1992; Stillman et al, 1998; Cordero et al, 2003; Joëls et al, 2006; Shansky et al, 2006; Luethi et al, 2008). Cost/benefit decision-making is a complex form of cognition mediated in part by the prefrontal cortex (PFC) that may be sensitive to acute stress. Some of the pioneering research on the topic stemmed from the observations that highly skilled pilots fell victim to battle-induced mental errors and poor decision-making during stressful circumstances (Broadbent, 1971). It is now understood that under conditions of acute stress, flexible decision-making dependent on normal PFC functioning is

*Correspondence: Dr SB Floresco, Department of Psychology and Brain Research Center, University of British Columbia, 2136 West Mall, Vancouver, BC V6T IZ4, Canada. Tel: + 604827 5313, Fax: + 604 822 6923, E-mail: floresco@psych.ubc.ca

Received 18 November 2011; revised 20 March 2012; accepted 9 April 2012 impaired (Arnsten, 1998), causing an organism to rely more on habitual behavior (Elliott and Packard, 2008). Recent laboratory studies in humans have begun to investigate how acute stress may alter decision-making using tasks designed to simulate real-life decisions, with respect to uncertainty, reward, and punishment. These studies have revealed that either acute cold stress or the administration of exogenous glucocorticoids impair decision-making by either decreasing the net gain of the subject over the session, or biasing the choice towards the riskier option when the chances of losing are higher (Miu et al, 2008; Porcelli and Delgado, 2009; Putman et al, 2010). Thus, acute stress may interfere with decision-making by altering the manner in which individuals evaluate the relative costs and benefits associated with different options, sometimes leading them to make more disadvantageous choices.

There has been a growing interest in modeling certain aspects of decision-making in experimental animals. One component process that can be assessed in rodents is the evaluation of costs associated with different candidate actions, relative to the potential rewards that may be obtained by those actions. Some response costs that are effective in biasing choice include making the delivery of the reward uncertain or risky, delaying its delivery, or requiring animals 
to exert greater physical effort to obtain a larger reward. Regarding this latter form of decision-making, it is notable that stress-related neuropsychiatric disorders, such as depression, are associated with anergia and other motivational deficits. This suggests that cost/benefit evaluations regarding effort requirements may be particularly susceptible to modulation by stress.

Effort-based decision is mediated by an interconnected neural network that includes the temporal, frontal, forebrain, and midbrain regions. Preference for larger, but costlier rewards is reduced by lesions/inactivation of the dorsomedial PFC (anterior cingulate; Walton et al, 2002, 2003; Schweimer and Hauber, 2005), basolateral amygdala (Floresco and Ghods-Sharifi, 2007; Ghods-Sharifi et al, 2009), and nucleus accumbens (NAc) (Hauber and Sommer, 2009; Ghods-Sharifi and Floresco, 2010). Dopamine (DA) also has a role in overcoming effort-related costs, as reducing DA activity either systemically or directly in the NAc or PFC reduces preference for higher effort/reward (HR) options (Cousins and Salamone, 1994; Salamone et al, 1991; Schweimer and Hauber, 2006). Interestingly, increasing DA activity with drugs such as amphetamine exerts differential dose-dependent effects. Lower doses increase preference for the HR option, whereas higher doses reduce preference for the HR (Floresco et al, 2008b).

It is notable that neural circuitry implicated in facilitating effort-based decision-making is particularly sensitive to acute stress. Prefrontal and limbic regions recruited by these processes show dense glucocorticoid receptor expression (Putman et al, 2010). Furthermore, there is considerable evidence that acute stress increases extracellular DA concentrations within the PFC, Nac, and amygdala (Roth et al, 1988; Abercrombie et al, 1989; Imperato et al, 1989, 1991; Davis et al, 1994; Finlay et al, 1995; Inglis and Moghaddam, 1999), which may in turn contribute to stressinduced alterations in cognitive functioning mediated by these systems. Thus, acute stress can cause enhancement in amygdala-dependent associative learning, classical conditioning, and contextual fear conditioning (Shors et al, 1992; Cordero et al, 2003; Joëls et al, 2006), but can impair PFCdependent working memory (Stillman et al, 1998; Shansky et al, 2006; Luethi et al, 2008). Therefore, the possibility remains that acute stress may interfere with effort-related judgments as it does with various types of cognition in animals and other forms of decision-making in humans.

To investigate this in more detail, we assessed the effects of acute restraint stress on effort-based decision-making, using an operant-based discounting task (Floresco et al, 2008b). Restraint is a well-characterized method of inducing stress in laboratory rodents, as it reliably increases circulating levels of stress-associated hormones, including adrenocorticotropic hormone and corticosterone (CORT; Kant et al, 1983, 1987; Williamson et al, 2005; Arnsten, 2009). Restraint stress disrupts cognition in rats (Shansky et al, 2006; Cordero et al, 2003) and induces reliable increases in DA release within the PFC and NAc (Roth et al, 1988; Abercrombie et al, 1989; Imperato et al, 1989, 1991; Finlay et al, 1995; Davis et al, 1994). The fact that this form of acute stress has been well-characterized in terms of its hormonal, dopaminergic, and cognitive effects made it an ideal approach for studying how acute stress may alter cognitive processes mediated by corticostriatal and dopaminergic circuitry. An initial study revealed that restraint stress altered effort-discounting. Subsequent experiments clarified the specific cognitive/motivational processes that were affected by stress, which may have contributed to the alterations in decision-making. Furthermore, we also investigated some of the hormonal and neurochemical mechanisms that may underlie these effects, specifically looking at the contribution of CORT and DA to the effects of stress on this form of decision-making.

\section{MATERIALS AND METHODS}

\section{Animals}

Different cohorts of male Long Evans rats (Charles River Laboratories, Montreal, QC, Canada) weighing 275-300 g, at the beginning of training, were used. Upon arrival, rats were given 1 week to acclimatize to the colony conditions, and were subsequently individually housed and food restricted to $85-90 \%$ of their free-feeding weight 1 week before behavioral training. Water was provided ad libitum for the duration of the experiment. Body weights were monitored daily, and food was provided in the animal's home cage at the end of each experimental day. All testing was done in accordance with the Canadian Council of Animal Care and the Animal Care Committee of the University of British Columbia. The number of animals used for each experiment ranged from 12 to 14 , with the exception of the reward magnitude discrimination and delay-discounting studies. qIn our experience, rats performing these latter tasks tend to display less intra-group variability, thereby requiring fewer animals to detect significantly reliable differences across treatment conditions.

\section{Apparatus}

All behavioral testing was conducted in operant chambers (30.5. $\times 24 \times 21 \mathrm{~cm}$; Med-Associates, St Alban, VT) enclosed in a sound-attenuating box. Boxes were equipped with a fan that provided ventilation and masked extraneous noise. Each chamber was fitted with two retractable levers, one located on each side of a central food receptacle, where food reinforcement ( $45 \mathrm{mg}$; Bioserv, Frenchtown, NJ) was delivered by a pellet dispenser. The chambers were illuminated by a single $100-\mathrm{mA}$ house light located in the top center of the wall opposite the levers. All experimental data were recorded by a personal computer connected to the chambers through an interface.

\section{Restraint Stress}

Acute stress was induced by restraining rats in a plexiglas semi-cylindric tube $(83 \times 133 \times 197 \mathrm{~mm}$; Harvard Apparatus, Massachusetts) in a quiet, lit, and ventilated room. Rats were placed in the tubes and a restrainer length was adjusted to keep the rat immobilized without causing pain. A desktop fan circulated air over the restraint tubes to minimize hyperthermia. Upon being removed from the restraint tube, animals were returned to their home cages and left undisturbed for $10 \mathrm{~min}$ before being placed in the operant chambers. In the first experiment, rats received two counterbalanced restraint stress sessions of differing durations $(20 \mathrm{~min}$ or 
$1 \mathrm{~h}$ ) on separate test days. In all other experiments, only the 1-h duration of restraint was used. For all experiments, 1-2 days before a stress test session, rats (in their home cages) were placed in the same room where stress manipulations would take place on the following day. They were left in the room for the amount of time corresponding to the duration of the stressor they would receive on the following day (20 min or, for most experiments $1 \mathrm{~h}$ ). There were no statistically significant differences in behavior across experiments between training sessions, where animals were placed in the stress-procedure room when compared with the regular training sessions. Therefore, baseline control data for all behavioral measures were obtained by computing an average of the particular measure recorded over the last 2 days before stress, which included data taken from a regular training session, and a session preceded by being placed in the stress-procedure room without restraint. These baseline values served as the key control data for which within-subjects statistical comparisons were made. For experiments where animals received multiple stressors, these tests were separated by at least 7 days.

\section{Initial Lever-Pressing Training}

Our initial training protocol has been described previously (Floresco et al, 2008a; Ghods-Sharifi et al, 2009). On the day before the first exposure to the operant chamber, rats were given approximately 20 reward pellets in their home cage. Before the animal was placed in the chamber for the first training session, two to three crushed pellets were placed inside of the food receptacle and on the active lever. Rats were trained under a fixed-ratio (FR)-1 schedule to a criterion of 60 presses in $30 \mathrm{~min}$, first for one lever, then the other (counterbalanced left/right between subjects). For rats that were to be trained on discounting tasks, subsequent sessions consisted of training on a simplified version of the full task, in which they had to act upon a retractable lever within $10 \mathrm{~s}$ of insertion. These sessions consisted of 90 training trials, and began with both levers retracted and the chamber in darkness. Every $40 \mathrm{~s}$, a trial was initiated with the illumination of the houselight and the extension of one of the two levers. If the rat failed to respond within $10 \mathrm{~s}$ after lever insertion, the lever was retracted, the chamber returned to darkness, and the trial was recorded as an omission, and the chamber was reset to the intertrial state. A response on the lever within $10 \mathrm{~s}$ of its insertion delivered one reward pellet. Rats were trained for approximately 5 days to a criterion of 80 successful trials (ie, $<10$ omissions), after which they were trained on the decisionmaking task.

\section{Behavioral Tasks}

We assessed the effects of acute restraint stress on a number of different behavioral tasks to obtain a comprehensive understanding of the manner in which stress may affect the effort-based decision-making. Separate groups of rats were trained and tested on a particular behavioral task before receiving stress and/or drug manipulations.

Effort discounting. The primary task used in these studies was an effort-discounting task we have described previously (Floresco et al, 2008b; Ghods-Sharifi et al, 2009; GhodsSharifi and Floresco, 2010). Each training day, animals received a 32-min session that consisted of 48 discrete trials, separated into 4 blocks. The format of a single trial is presented in Figure 1. A session began with the chamber in darkness and both levers retracted (the intertrial state). At 40-s intervals, the houselight was illuminated, followed by the extension of one or both levers $3 \mathrm{~s}$ later. Each of the 4 trial blocks began with two forced-choice trials, where only one of the two levers was randomly presented. During the next 10 trials, both levers were presented. One lever was designated as the low-reward (LR) lever, and the other lever was designated as the HR lever. These levers were counterbalanced (left/right) between animals and remained constant for each animal for the duration of the experiment. Upon lever insertion, rats were required to respond within $25 \mathrm{~s}$; failure to do so (omission) caused the chamber to reset to the intertrial state. A single press of the LR lever resulted in the retraction of both levers and immediate delivery of two pellets. However, after the first response on the HR lever, the LR lever was retracted, and the HR lever remained inserted until the required ratio of presses was completed. The ratio requirement for the HR lever increased within the session. Upon completion of the required effort ratio on the HR lever, the lever retracted and four pellets were delivered $0.5 \mathrm{~s}$ apart. The houselight remained on for $4 \mathrm{~s}$ after food delivery.

The fixed effort ratio of lever presses required to obtain the HR increased over the 4 blocks of trials, beginning with 2 presses, then 5,10 , and 20 presses. On the rare occurrence when a rat failed to complete the required number of

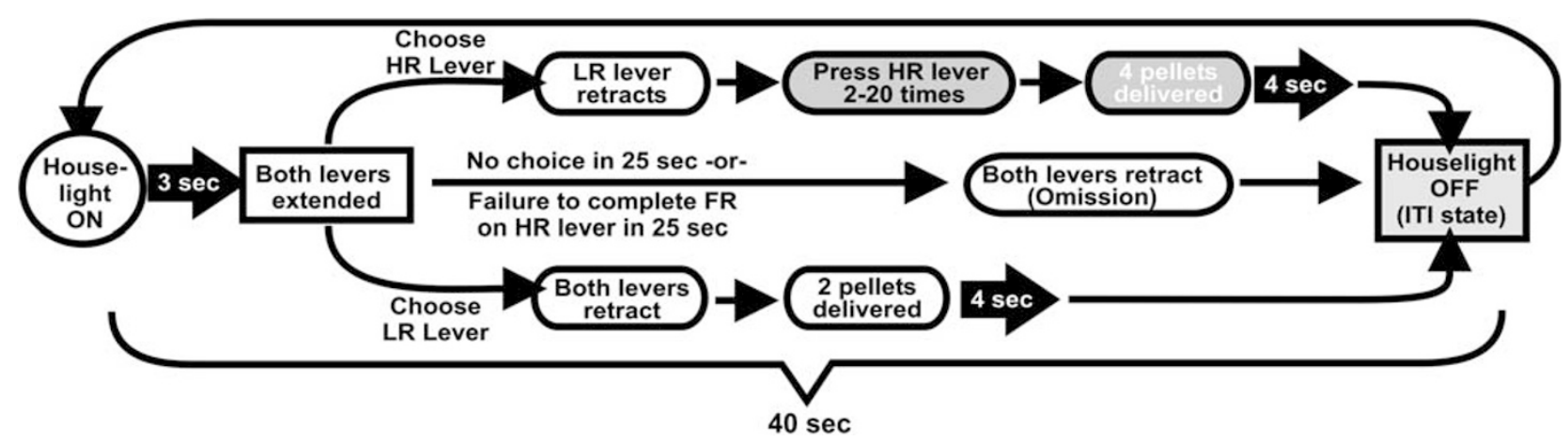

Figure I The format of a single free-choice trial on the effort-discounting task. 
presses on the HR lever within $25 \mathrm{~s}$ after insertion, the lever retracted without food delivery. However, the animal's choice was still incorporated into the data analysis. In addition, latencies to initiate a lever press and complete the required number of presses on the HR lever were recorded.

Rats were trained on the effort-discounting task until as a group, they (1) chose the HR lever during the first trial block on at least $75 \%$ of successful trials, and (2) demonstrated stable baseline levels of discounting for 3 consecutive days. Stability was assessed using statistical procedures similar to that described by Floresco et al (2008b) and St Onge and Floresco (2009). Data from three consecutive sessions were analyzed with a repeated-measures ANOVA with two within-subjects factors (training day and trial block). If the effect of block was significant at the $p<0.05$ level but there was no main effect of day or day $\times$ trial-block interaction (at $p>0.1$ level), animals were judged to have achieved stable baseline levels of choice behavior.

Reward magnitude discrimination. This task was similar to the effort-discounting task (ie, 48 trials, 4 trial blocks, 2 forced choice $/ 10$ free choice trials per block, $40 \mathrm{~s}$ intertrial interval), with the key exception that a single press of either the LR or HR lever caused the immediate delivery of either 2 or 4 pellets. Thus, animals merely had to choose between a smaller or larger reward, with no additional cost associated with the HR option. Rats were trained for 9 days, after which they displayed a strong preference for the HR lever ( $90 \%)$. They were subsequently subjected to a baseline session, followed by a 1-h restraint stress challenge on the next day.

Effort-discounting with equivalent delays. This modified version of the effort-discounting task assessed the contribution that delays to reward delivery intertwined with effort requirements made to decision-making. Rats were trained for 16 days on the standard effort-discounting task, and were then trained on a modified version of the original task. Here, a single press on the LR lever caused the immediate retraction of both levers and delivered two pellets after a delay equivalent to that required for rats to complete the ratio of presses on the HR, using the standard effortdiscounting procedure (0.7-12.5 s). Thus, for each block of trials, the delay to reward delivery after an initial choice of either lever was equalized. The delay to receive two pellets after a single press on the LR lever increased across trial blocks and was calculated on the basis of the average time it took the rats to press the HR lever 2, 5, 10, and 20 times during the last 3 days of training on the effort-discounting task. Thus, if rats required $12.5 \mathrm{~s}$ to press the HR lever 20 times during the last trial block, a single press on the LR lever during this block would deliver two pellets after a $12.5 \mathrm{~s}$ delay. During these trials, the houselight remained illuminated throughout the delay. Rats received 8 training sessions with this task (in addition to the 16 sessions with the standard effort-discounting task), at which point they displayed stable levels of choice for 3 consecutive days. On the following day, they were subjected to the baseline control test followed by a restraint stress challenge on the next day.

Delay-discounting. In this experiment, rats received initial lever training as described previously. They then received 1 day of reward magnitude discrimination (four $v s$ one pellet). Subsequently, they received daily training sessions on a delay-discounting task (Zeeb et al, 2010). Like the effort-discounting procedure, this task consisted of 48 trials, divided into 4 trial blocks (first 2 forced, next 10 freechoice). The intertrial interval was $70 \mathrm{~s}$ (56-min session). On each trial, a single press on the LR lever retracted both levers and delivered one pellet immediately. Selection of the HR lever also retracted both levers and delivered four pellets after a delay that increased across the four trial blocks $(0,15,30$, and $45 \mathrm{~s})$. During the delay, the houselight was extinguished and re-illuminated during food delivery at the end of the delay.

Progressive ratio tests. In this experiment, only the left lever was inserted into the chamber and remained in place for the duration of each training session. During the initial 4 days of training, rats learned over 30 -min sessions to press the lever for a single reward pellet, using FR-1, FR-2, and then FR-5 schedule. They then received daily training sessions on a progressive ratio schedule, in which the ratio of presses required to obtain a single pellet increased after each pellet delivery. The ratio increased in the following manner: $1,2,4,6,9,12,15,20,25,32,40,50,62,77,95,118$, $145,178,219,268,328,402,492,693,737$, and 901 presses (Brown et al, 1998). Rats had a maximum of $20 \mathrm{~min}$ to complete each ratio; failure to do so ended the session. The primary variables of interest were: (1) the total number of lever presses made over the course of a session and (2) the total number of rewards obtained before a session terminates (breakpoint).

\section{CORT Challenge}

The effects of acute CORT treatment on effort-based decision-making were assessed using a within-subjects design. Rats were trained on the standard effort-discounting task until they displayed stable levels of choice. They were then subjected to the first of two injection test days. Each test day was part of a 2-day sequence. After injections, rats were returned to their home cage and left undisturbed for 90 min, after which they received a training session. On the first day, all rats received a vehicle injection (50/50 propylene glycol $/ 0.9 \%$ saline, s.c.). On the subsequent day, rats were split into two groups and matched for choice behavior after vehicle injections, and then received their first counterbalanced injection of CORT ( 1 or $3 \mathrm{mg} / \mathrm{kg}$, Sigma Aldrich). After this first test-day sequence, rats were retrained for 4 days until they again displayed stable baseline levels of choice. They then received a second injection test-day sequence (ie, vehicle injection on the first day, and a counterbalanced injection of either 1 or $3 \mathrm{mg} / \mathrm{kg}$ CORT on the second day). The doses of CORT used and the time course of administration were originally derived from studies showing that they approximate increases in CORT release occurring during comparable durations of restraint stress (Meaney et al, 1988; Imperato et al, 1991).

\section{Plasma CORT Assay}

To compare CORT levels induced by injections (vehicle, 1.0 and $3.0 \mathrm{mg} / \mathrm{kg}$ ) and $1 \mathrm{~h}$ of restraint exposure, tail vein blood samples were repeatedly collected in separate groups of animals not used for behavioral testing, immediately following removal from home cage $(0 \mathrm{~min})$, and at 30,60 , and $90 \mathrm{~min}$ 
after initial s.c. injections, or from restraint onset. Plasma levels of CORT were measured in duplicate using the RIA kit from MP Biomedicals (Solon, $\mathrm{OH}$ ) as previously described (Gray et al, 2010), undertaken in a single analysis to avoid inter-assay variability, with an intra-assay coefficient of variation of $6 \%$.

\section{DA Antagonism}

The contribution of DA transmission to the stress-induced alterations of effort-discounting was assessed with a withinsubjects design. Rats were trained on the effort-discounting task until they displayed stable baseline levels of choice behavior at 3 consecutive days. They were then subjected to the first of 4 test days: (1) saline/no stress, (2) saline/stress, (3) flupenthixol/no stress, or (4) flupenthixol/stress. Rats were split into four groups of three, with each group receiving the four tests in a counterbalanced order, using a quasi-Latin Square design. This was done to control for any potential habituation to the stressor that may have occurred following repeated exposure to restraint. With this design, none of the rats in any of the groups were subjected to restraint stress on consecutive test days. For example, rats first assigned to the saline/no stress condition subsequently received saline/ stress on the second test day, followed by the flupenthixol/ no stress condition on the third test day and so on.

On the first test day, all animals were injected with either saline or a low dose of flupenthixol $(0.25 \mathrm{mg} / \mathrm{kg}$, i.p., Sigma Aldrich) and then returned to their home cage for $10 \mathrm{~min}$. They were then subjected to either $1 \mathrm{~h}$ of restraint stress, or left undisturbed in their home cage in a room similar to the stress procedure room for $1 \mathrm{~h}$. Behavioral testing for each commenced $10 \mathrm{~min}$ after being removed from the restraint tube/control room. Each subsequent test day was administered when choice behavior of rats within a particular subgroup was stable for 2 consecutive days. For this particular experiment, rats required a minimum of 5 and a maximum of 8 days of retraining between test days.

\section{RESULTS}

\section{Effects of Different Durations of Acute Restraint Stress on Effort-Discounting}

The primary aim of this experiment was to determine whether acute restraint stress alters different aspects of effort-based decision-making. A secondary aim was to determine if there is a 'threshold' of stress duration that would affect decision-making. Rats $(n=14)$ were trained for 22 days on the effort-discounting task, after which they displayed stable levels of choice behavior. They subsequently received the first of two counterbalanced stress tests of either $20 \mathrm{~min}$ or $1 \mathrm{~h}$ in duration. After the first session of restraint, rats were retrained for 7 days before receiving their second stress test. Baseline choice of the HR lever before $20 \mathrm{~min}$ or $1 \mathrm{~h}$ stress test days did not differ, and were thus averaged and used for the data analysis.

Restraint stress induced a marked decrease in the preference to work harder for a larger reward. Choice data were analyzed with a three-way between/within subjects ANOVA, with the order of stress duration (20 min or $1 \mathrm{~h}$ restraint) as a between-subjects factor, and test day (baseline, $20 \mathrm{~min}$ or
$1 \mathrm{~h}$ stress) and trial block as two within-subjects factors. This analysis revealed a significant effect of test day $\left(F_{2,24}=7.94, p<0.005\right)$, but not a significant test day $\times$ trial block interaction $\left(F_{6,72}=1.15\right.$, n.s. $)$. Multiple comparisons confirmed that 1 -h restraint stress significantly $(p<0.05)$ decreased choice of the HR lever relative to baseline (Figure 2a). This effect was apparent in the first trial block,
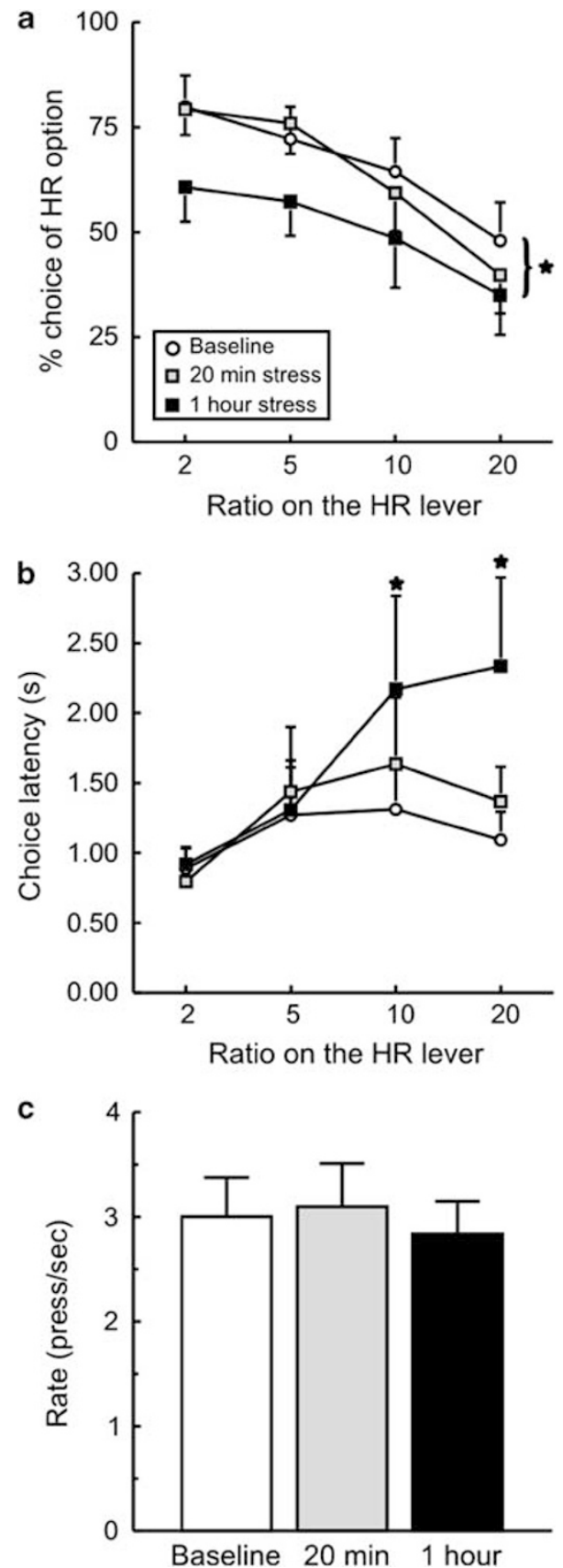

Figure 2 Effects of acute restraint stress ( $\mathrm{h}$ and $20 \mathrm{~min}$ ) on effortdiscounting. (a) The ordinate shows the percent choice of the HR lever across the four trial blocks and the abscissa indicates the four trial blocks with increasing effort ratio; I h and not 20 min restraint decreased the selection of the HR option across all trial blocks. (b) The response latency across trial blocks; I h restraint increased the latency to respond in the third and fourth trial block. (c) Acute restraint stress did not affect the rates of pressing on the HR lever. Stars denote significant main effect of treatment at $p<0.05$. 
and persisted over the duration of the session. In comparison, $20 \mathrm{~min}$ of restraint induced a smaller decrease in preference for the HR lever in the last trial block (20 presses), but this effect did not achieve statistical significance. Notably, there was no main effect of the order of stress duration, or any interactions with the within-subjects factors (all Fs $<2.27$, n.s.), indicating that rats initially exposed to $20 \mathrm{~min}$ stress showed alterations in behavior after $1 \mathrm{~h}$ stress comparable to rats that received $1 \mathrm{~h}$ stress on the first test day.

Acute stress also led to longer latencies to make a choice. These data were analyzed in a manner similar to the choice data, and revealed a significant test day $\times$ trial block interaction $\left(F_{6,72}=2.67, p<0.05\right.$; Figure $\left.2 b\right)$. Simple main effects analysis confirmed that $1 \mathrm{~h}$ (but not $20 \mathrm{~min}$ ) restraint significantly increased choice latencies during the last two trial blocks when the effort requirements on the HR lever were 10 and 20 presses, respectively. Again, there was no main effect of the order, or any interactions with the withinsubjects factors (all $F s<1.17$, n.s.).

In contrast to the effect on choice latencies, acute stress did not alter the rates of lever pressing (press/sec) on the HR lever $\left(F_{2,24}=1.02\right.$, n.s.; Figure $\left.2 \mathrm{c}\right)$. Thus, even though $1 \mathrm{~h}$ stress decreased the overall preference for the HR lever, on trials where rats choose this option, they responded as robustly as they did after $20 \mathrm{~min}$ of stress or on baseline days. Stress did not increase the number of trial omissions (baseline: $0.48 \pm 0.21,20 \mathrm{~min}: 1.21 \pm 0.85,1 \mathrm{~h}: 1.86, \pm 1.036$; $F_{1,13}=0.002$, n.s.). Collectively, these data suggest that $1 \mathrm{~h}$ of restraint stress causes a substantial decrease in the preference for animals to work harder to obtain a larger reward, and also led to longer deliberation times when the HR option is associated with a relatively high effort cost. As only the $1 \mathrm{~h}$ stressor was effective at altering choice behavior and response latencies on the effort-discounting task, all subsequent experiments only used this duration of restraint.

\section{The Effects of Acute Restraint Stress on Reward Magnitude Discrimination}

One potential explanation for the effects of stress on effortdiscounting is that it may have caused a decrease in the subjective preference for objectively larger rewards. To address this possibility, we assessed the effects of $1 \mathrm{~h}$ acute stress on a reward magnitude discrimination task. A separate group of rats $(n=8)$ were trained for 9 days before receiving baseline and stress test days. Stress did not decrease the preference for the HR option (main effect of test day $\left(F_{1,7}=1.577\right.$, n.s. $)$; test day $\times$ trial block interaction $\left(F_{3,21}=1.56\right.$, n.s.; Figure 3a). However, as was observed in the previous experiment, acute stress did increase response latencies (main effect of test day; $F_{1,7}=16.84, p<0.005$; Figure $3 \mathrm{~b}$ ). Again, trial omissions were unaffected by acute stress (baseline: 0, $1 \mathrm{~h}$ : 0). Thus, acute stress did not disrupt the general preference for larger $v s$ smaller rewards, but again increased deliberation times to make a selection.

\section{Effect of Acute Restraint Stress on Effort-Discounting with Equivalent Delays}

With the effort-discounting task, choice of the high effort option imposes a delay from the time of the initial choice to when the reward is delivered. It is possible that the stressinduced decrease in the preference for the HR option may reflect decreased tolerance for delayed rewards rather than a decreased tolerance for greater effort demands. One manner to evaluate this hypothesis is to employ an equivalent delay procedure in combination with the effort-discounting task. This task has previously been used to dissociate between the effort and delay requirements embedded within the effortdiscounting task (Floresco et al, 2008b; Ghods-Sharifi et al, 2009; Ghods-Sharifi and Floresco, 2010). In this task, the effort requirement to obtain the LR/HR was identical to the standard task, but selection of the LR option incurred a delay to reward delivery comparable to the time required to complete the ratio of presses on the HR lever. Thus, this procedure effectively equalizes the relative delay costs associated with the HR and LR options.

A separate group of rats $(n=13)$ were initially trained on the effort-discounting task for 16 days, followed by another 8 days of training using the equivalent delays procedure. For this experiment, the average delays before delivery of the LR were set at $0.7,2.6,6.1$, and $12.5 \mathrm{~s}$ for each respective block. Restraint stress markedly decreased preference to work harder for the HR when delays to reward delivery were equalized across the two options. A two-way ANOVA revealed a significant effect of test day $\left(F_{1,12}=6.93, p<0.05\right)$, but not a significant test day $\times$ trial block interaction $\left(F_{3,36}=1.12\right.$, n.s.). This decrease in choice of the HR was apparent in the first trial block and persisted for the duration of the session (Figure 4a).
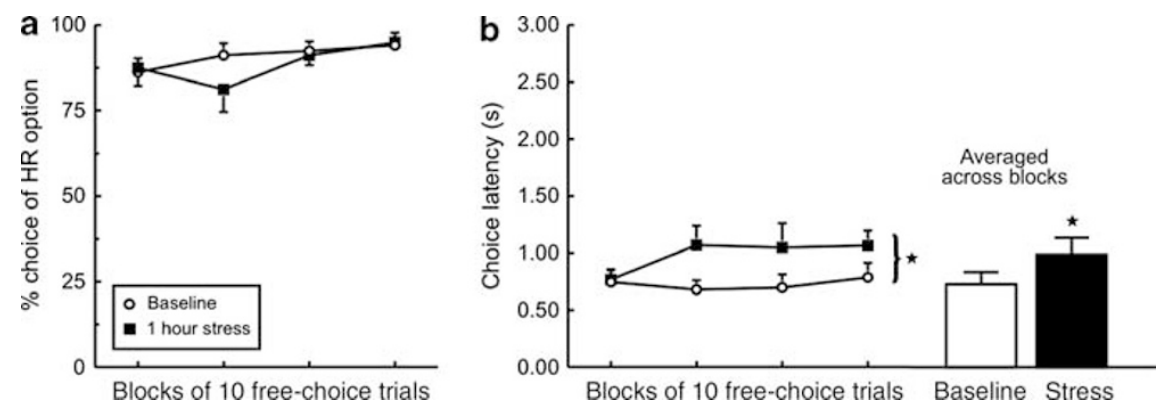

Figure 3 Effects of acute restraint stress on performance in a reward magnitude discrimination task. (a) Acute restraint stress did not alter preference for the HR option when there was no additional cost associated with it. (b) Response latencies across each block of 10 free-choice trials (left) and averaged across the four trial blocks (right). Acute restraint stress increased the latency to make a choice. Stars denote significant main effect where $p<0.05$. 

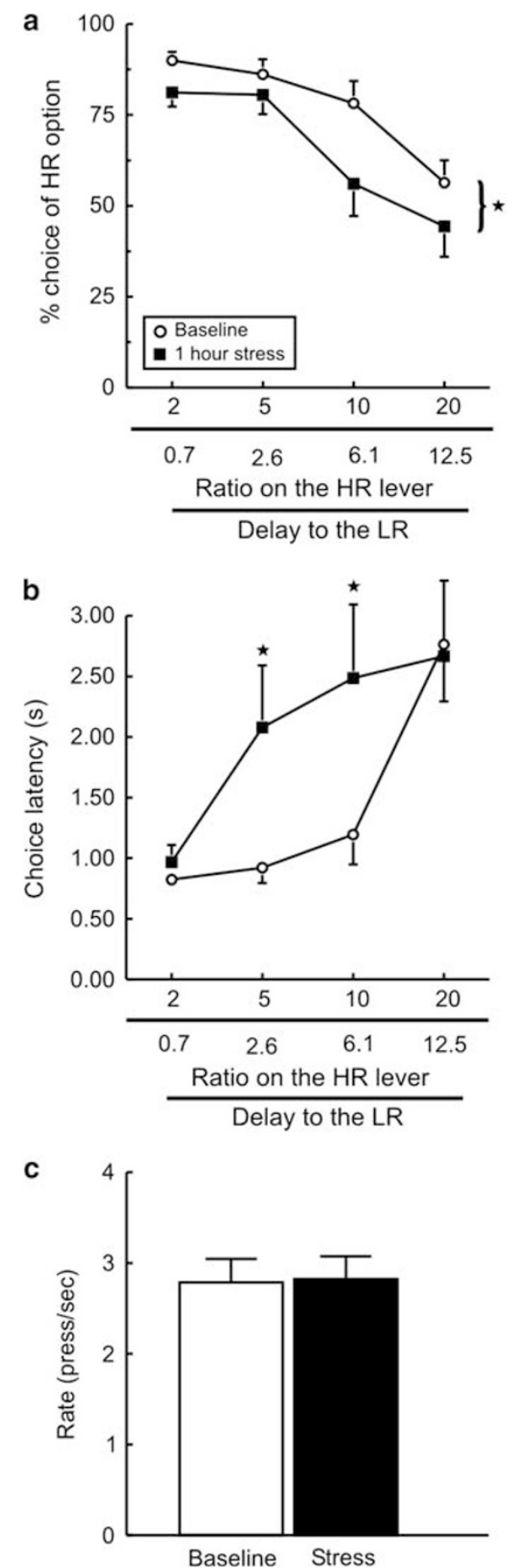

Figure 4 Effects of acute restraint stress on effort-based decision-making with equivalent delays. (a) The ordinate shows the percent choice of the $H R$ and the abscissa indicates the four trial blocks with increasing effort ratio of the HR (top) and increasing delay to reward delivery of the LR (bottom). Acute restraint stress decreased the selection of the HR option even when the delays to the delivery of the LR were similar. (b) Response latencies across the four trial blocks. Acute restraint stress increased the latency to respond in the second and third trial block. (c) Acute restraint stress did not affect the rates of lever pressing. Stars denote significant main effect where $p<0.05$.

Acute stress also yielded longer response latency in a manner similar to that observed in experiment 1 . Analysis of these data revealed a significant test day $\times$ trial block interaction $\left(F_{3,36}=3.37, p<0.05\right)$. Simple main effects analyses confirmed that after $1 \mathrm{~h}$ of restraint, the response latency in the second and third trial blocks were significantly longer $(p<0.05)$ than baseline (Figure $4 \mathrm{~b})$. However, stress again did not alter the average rates of lever pressing on the HR lever $\left(F_{1,12}=0.12\right.$, n.s.; Figure $\left.4 \mathrm{c}\right)$. Additionally, stress did not alter the number of trial omissions (baseline: $2.54 \pm 1.24,1 \mathrm{~h}: 4.7 \pm 2.30 ; F_{1,12}=1.71$, n.s.). Thus, $1 \mathrm{~h}$ of restraint stress substantially decreased preference for animals to work harder to obtain a larger reward even when the delays to reward delivery between the $H R$ and the LR options were equalized.

\section{Effects of Acute Restraint Stress on Delay-Discounting}

The possibility remained that acute stress may also affect other forms of cost/benefit decision-making related to choice between smaller/immediate and larger/delayed rewards. This was investigated using a delay-discounting task, a wellestablished method of assessing impulsive choice.

A separate group of rats $(n=8)$ were trained on a delaydiscounting task for 25 days before receiving baseline and stress test days. Restraint stress did not alter delay-discounting (main effect of test day $\left(F_{1,7}=1.12\right.$, n.s.)); test day $\times$ trial block interaction $\left(F_{3,21}=1.46\right.$, n.s.; Figure $\left.5 a\right)$. Interestingly, in this experiment, restraint stress did not alter choice latencies (all $F s<3.17$, n.s.; Figure 5b). Furthermore, stress did not alter the number of trial omissions (baseline: $1 \pm 0.27,1 \mathrm{~h}: 0.625, \pm 0.18, F_{1,7}=1.615$, n.s.). Thus, in contrast to the effects of restraint on effort-related decisions, acute stress does not appear to reduce preference for larger, delayed rewards.

\section{Effect of Acute Restraint Stress on Responding on a Progressive Ratio Schedule of Reinforcement}

It is possible that the effects of acute stress on effort-based decision-making may reflect a disruption in certain motivational processes, which may in turn interfere with effortrelated judgments. For example, acute stress may render animals either unwilling or unable to respond on a lever repeatedly to obtain a reward. This possibility was assessed using a progressive ratio schedule of reinforcement.

A group of 13 rats were initially trained over 4 days to press a lever on a FR-1, FR-2, and then FR-5 schedule. Rats were then trained using a progressive ratio schedule for 22 days, after which the group displayed stable levels of lever pressing and breakpoints for 3 consecutive days (ie, $<15 \%$ variation within the group). Acute stress did not alter responding on a progressive ratio of reinforcement. Analysis of the total number of lever presses and breakpoints reached confirmed no significant differences on these measures on baseline vs stress test days (total lever presses: $F_{1,12}=0.85$, n.s.; breakpoints: $F_{1,12}=0.14$, n.s.; Supplementary Fig 1A, B). Rates of lever pressing on baseline and stress test days were also analyzed. On the stress test days, all rats successfully completed the first eight ratio requirements; however, the final breakpoint varied across rats. We calculated the average rates of lever pressing to obtain the first seven and the final two pellets on baseline and stress test days. Stress did not alter rates of lever pressing relative to baseline, (main effect of test day; $F_{1,12}=1.905$, 

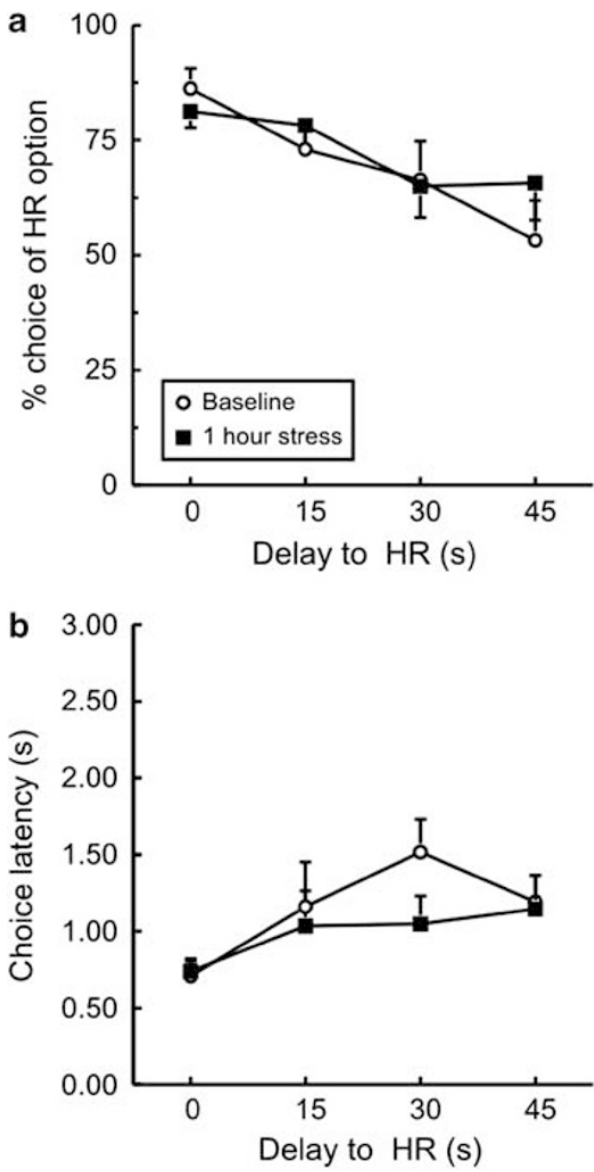

Figure 5 Effects of acute restraint stress on delay-discounting. (a) The ordinate shows the percent choice of the HR lever and the abscissa indicates the delays to HR delivery across the different trial blocks. Acute restraint stress did not alter the choice of the delayed HR. (b) Response latency across the four trial blocks. Acute restraint stress did not alter response latencies when choosing between a delayed HR and an immediate LR.

n.s.; test day $\times$ pellet interaction $F_{8,96}=1.464$, n.s.; Supplementary Fig 1C). These findings are consistent with the lever pressing and breakpoint data, indicating that acute restraint stress does not appear to cause a general reduction in motivation to work for food.

\section{The Effects of Exogenous CORT on Effort-Based Decision-Making}

Restraint stress increases the release of CORT, which in turn mediates numerous physiological, neural and behavioral changes associated with stress. To probe whether the effects of acute restraint on effort-based decision-making were attributable to increases in CORT activity, we investigated whether administration of exogenous CORT could alter effort-discounting in a manner similar to acute restraint stress.

A group of 12 rats were trained on the effort-discounting task for 30 days before receiving injections of vehicle or CORT on separate test days. Choice data from these challenge sessions were analyzed using a threeway between/within-subjects ANOVA, with the order of treatment ( 1 or $3 \mathrm{mg} / \mathrm{kg}$ CORT first) as a between-subjects factor, and dose (vehicle, 1 and $3 \mathrm{mg} / \mathrm{kg}$ CORT) and trial block as two within-subjects factors. The behavioral parameters of interest did not differ between the first and second vehicle injections (all $F s<1.9$, n.s.). Thus, the average values of these measures were used for the data analysis. As displayed in Figure 6a, treatment with either dose of CORT did not alter preference for the HR lever relative to vehicle (main effect of dose: $F_{2,20}=0.004$, n.s.; dose $\times$ block interaction: $F_{2,20}=1.16$, n.s.). There were also no effects of the order of treatment or interactions with the within-subjects factors (all $F s<1.74$, n.s.). Similarly, there were no effects of CORT on choice latencies (Figure 6b), trial omissions (vehicle: $0.17 \pm 0.11,1 \mathrm{mg} / \mathrm{kg}$ : $0.25 \pm 0.13$, $3 \mathrm{mg} / \mathrm{kg}: 0.33 \pm 0.14$ ) or lever presses per second (vehicle: $3.6 \pm 0.4,1 \mathrm{mg} / \mathrm{kg}: 3.6 \pm 0.4,3 \mathrm{mg} / \mathrm{kg}$ : $3.7 \pm 0.5$; all $p>0.35$ ). Thus, administration of exogenous CORT did not mimic the effects of acute restraint stress on effort-discounting or other behavioral measures.

To confirm that increases in CORT plasma levels induced by exogenous treatment with the hormone were comparable to those experienced by rats subjected to $1 \mathrm{~h}$ restraint stress, we conducted another experiment in separate groups of rats ( $n=6$ per group). Specifically, we assessed changes in plasma CORT levels relative to baseline after $1 \mathrm{~h}$ restraint, or injections of vehicle, 1 or $3 \mathrm{mg} / \mathrm{kg}$ CORT. Blood samples were taken before restraint/injections, and then 30,60 and 90 min after the respective manipulation. For animals in the injection groups, the $90 \mathrm{~min}$ time point represented the time after vehicle/CORT treatment when testing would have commenced for rats in the behavioral experiment. For those in the restraint condition, the $60 \mathrm{~min}$ time point corresponded to when rats in our behavioral studies were released from restraint, $10 \mathrm{~min}$ before when behavioral testing was initiated.

Changes in plasma concentrations of CORT were analyzed using a two-way repeated measures ANOVA, which yielded a significant main effect of treatment $\left(F_{3,20}=52.54, p<0.001\right)$ and treatment $\times$ time interaction $\left(F_{3,60}=37.73, p<0.001\right)$. As displayed in Figure $6 c$, restraint stress increased plasma CORT at the 30-min mark, followed by an additional increase by $60 \mathrm{~min}$, and then decreasing at $90 \mathrm{~min}$ (ie, $30 \mathrm{~min}$ after release from restraint), although levels at this point were still significantly $(p<0.05)$ elevated relative to controls. Injection with 1 or $3 \mathrm{mg} / \mathrm{kg}$ CORT caused an increase in plasma levels that was significantly higher (Tukey's, $p<0.05$ ) than those induced by restraint at the $30-\mathrm{min}$ mark. By $60 \mathrm{~min}$, the $1 \mathrm{mg} / \mathrm{kg}$ dose yielded levels comparable to restraint, whereas rats treated with $3 \mathrm{mg} / \mathrm{kg}$ continued to display higher levels of plasma CORT compared with restrained rats. To directly compare relative changes in CORT exposure induced by $1 \mathrm{~h}$ after restraint to those displayed $90 \mathrm{~min}$ after CORT injections, integrated hormone levels were determined with the trapezoidal rule, and the data expressed over time of sampling (area under the curve/time). As shown in Figure 6d, injections of either dose of CORT yielded areas under the curve after $90 \mathrm{~min}$ that were actually higher than those observed after $1 \mathrm{~h}$ restraint $(60$-min mark, both $t \mathrm{~s}(10)>9.70$, both $p s<0.001)$. When comparing these values at the $90 \mathrm{~min}$ time point across all groups, levels induced by the $3 \mathrm{mg} / \mathrm{kg}$ dose were still higher $(p<0.05)$ than those observed in the restraint 

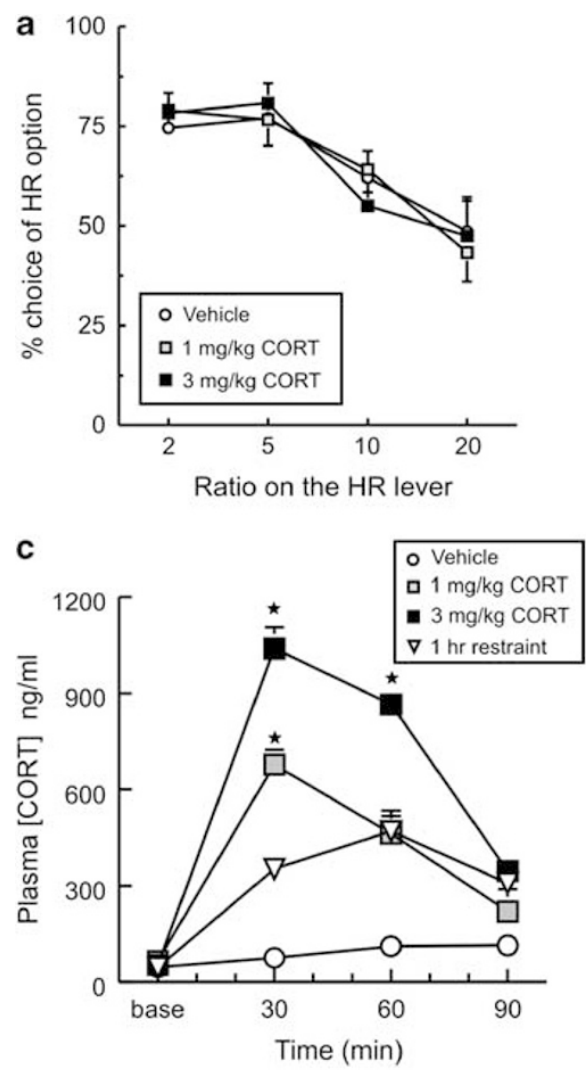

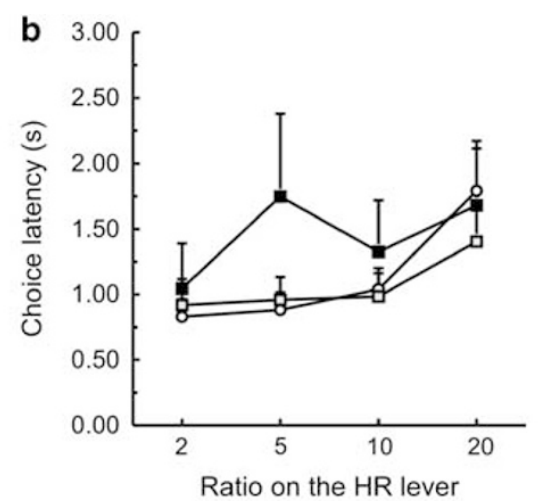

d

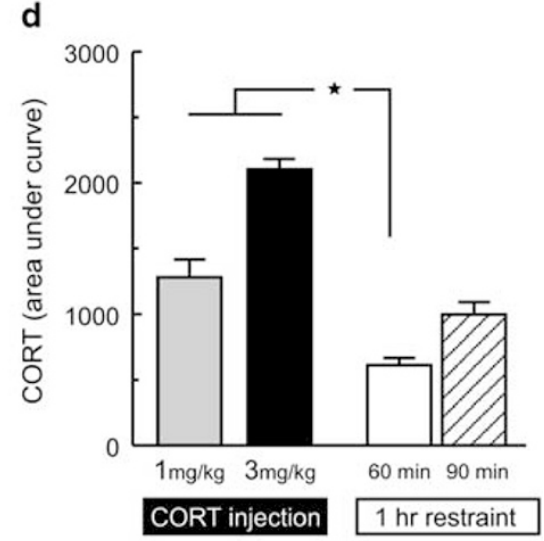

(90 $\mathrm{min})$

Figure 6 Effects of exogenous corticosterone (CORT) administration ( I and $3 \mathrm{mg} / \mathrm{kg}$ ) on effort-based decision-making. (a) Choice behavior following the administration of either dose of CORT was comparable to choice after vehicle injection. (b) Similarly, response latencies were not affected by exogenous CORT relative to vehicle treatment. (c) Mean \pm SEM plasma CORT concentrations taken at baseline, and 30, 60, and 90 min after I h restraint and s.c. injections of vehicle, I and $3 \mathrm{mg} / \mathrm{kg}$ CORT. Stars denote significant difference vs restraint at $p<0.05$. (d) Integrated (area under curve/time) plasma hormone responses to I and $3 \mathrm{mg} / \mathrm{kg}$ CORT injections over the entire 90-min period, compared with values obtained from retrained rats subjected to restraint rats taken from baseline $60 \mathrm{~min}$ (white bar) and baseline $90 \mathrm{~min}$ (hatched bar). Injections of either dose of CORT resulted in higher integrated plasma levels over $90 \mathrm{~min}$ (stars denote $p<0.05$ ) compared with those observed following I h of restraint.

group. Thus, these data confirm that injections of $1-3 \mathrm{mg} / \mathrm{kg}$ of exogenous CORT increases plasma CORT to levels that are comparable or even higher than those experienced following $1 \mathrm{~h}$ restraint stress. As such, the lack of effect of CORT injections on effort-discounting (when compared with restraint) is unlikely to be due to insufficient dosing with exogenous CORT.

\section{Dopaminergic Contribution to the Effects of Acute Stress on Effort-Based Decision-Making}

It is well-established that acute stress (including restraint) increases DA release in forebrain regions such as the PFC and NAc, and that these increases may underlie disruption in more complex cognitive functioning induced by stress (Roth et al, 1988; Abercrombie et al, 1989; Imperato et al, 1989, 1991; Davis et al, 1994; Finlay et al, 1995). Notably, increasing endogenous release of DA with higher doses of drugs such as amphetamine alters effort-based decisionmaking in a manner similar to that induced by acute restraint stress, decreasing preference for a high effort/HR option on an effort-discounting task (Floresco et al, 2008b; Floresco and Whelan, 2009). Therefore, it is possible that the effects of acute stress observed in our previous experiments may be meditated by excessive increases in endogenous DA. To test this hypothesis directly, we assessed how treatment with a low dose of the broad-spectrum DA antagonist flupenthixol $(0.25 \mathrm{mg} / \mathrm{kg})$ altered the effects of acute $1 \mathrm{~h}$ restraint stress on effort-related choice and response latencies. In this experiment, flupenthixol was administered $10 \mathrm{~min}$ before the start of restraint stress. As this compound has a particularly long half life ( $>19 \mathrm{~h}$, Jorgensen et al, 1971), this procedure would be expected to block DA receptors during the initial increase in DA release that occurs during restraint, and during increased efflux occurring after release from restraint (Imperato et al, 1991). With respect to dosage, previous work in our laboratory has shown that a higher, $0.5 \mathrm{mg} / \mathrm{kg}$ dose of flupenthixol causes a robust and reliable decrease in preference for the HR lever on this task, whereas $0.125 \mathrm{mg} / \mathrm{kg}$ does not significantly alter preference (Floresco et al, 2008b). As both acute stress and higher doses of this DA antagonist reduces choice of the high effort/HR option on this task, we used $0.25 \mathrm{mg} / \mathrm{kg}$ dose in an attempt to block stress-induced alterations in decisionmaking without occluding these effects by the direct action of the drug itself.

A group of 12 rats were trained on the effort-discounting task for 40 days, after which they were subjected to the first 
of four counterbalanced test days: (1) saline/no stress, (2) saline/stress, (3) flupenthixol $(0.25 / \mathrm{mg}) /$ no stress, or (4) flupenthixol/stress (see Figure 7f). Choice data were analyzed with a three-way between/within-subjects ANOVA, with stress condition (no stress and stress), drug treatment (saline and flupenthixol), and trial block as three within-subjects factors. This analysis revealed a significant main effect of stress $\left(F_{1,11}=6.76, p<0.05\right)$, but no stress $\times$ trial block interaction $\left(F_{3,33}=2.29\right.$, n.s. Figure $\left.7 \mathrm{a}\right)$. Thus, across drug/saline treatments, restraint stress decreased the overall preference to work harder for a larger reward without differentially altering the rate of discounting across blocks, replicating our effects observed in prior experiments.
Importantly, there was no main effect of drug on choice $\left(F_{1,11}=0.44\right.$, n.s. $)$, indicating that this dose of flupenthixol, administered $80 \mathrm{~min}$ before behavioral testing was insufficient to alter decision-making. Of particular note, the analysis did not yield significant stress $\times$ drug or stress $\times$ drug $\times$ trial block interaction (all $F s<0.87$, n.s.). Thus, there were no differential effects of acute stress on choice after saline or flupenthixol treatment. This is demonstrated in Figure $7 \mathrm{~b}$ and $\mathrm{c}$, which show that although $1 \mathrm{~h}$ of restraint stress decreases selection of the HR option, administration of flupenthixol before the stressor did not alter these effects when compared with the saline/stress treatment.

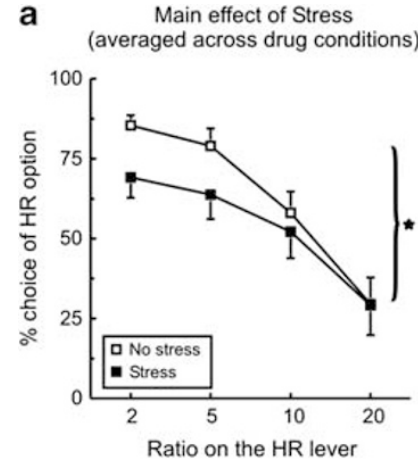

d
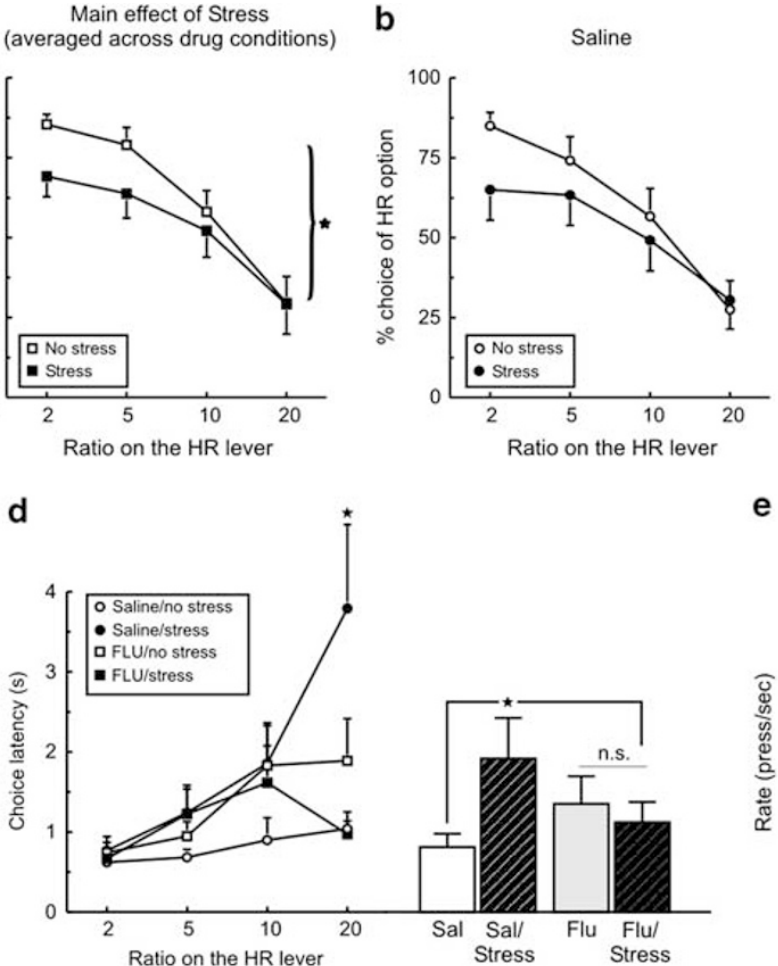
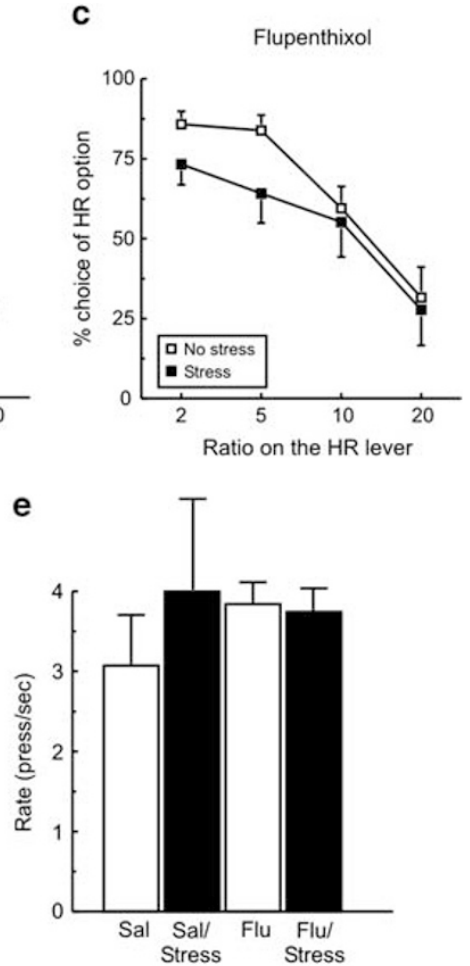

f

Treatment counterballancing orders

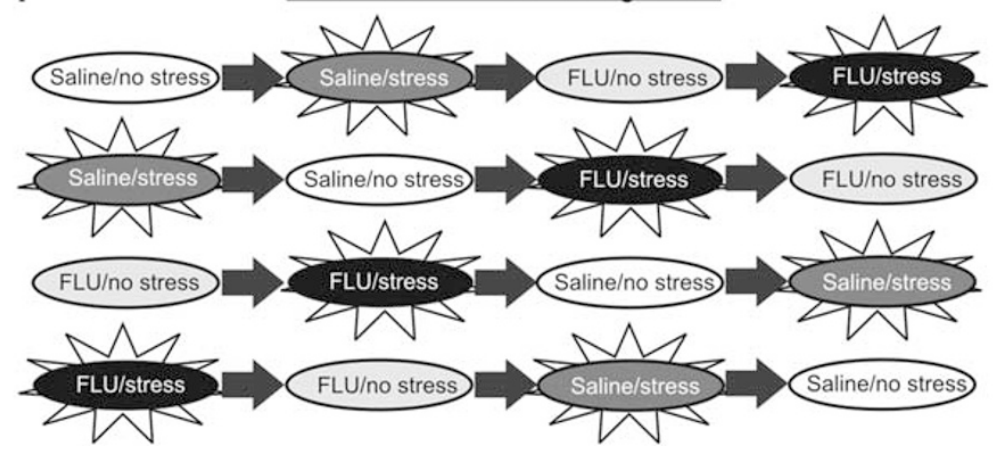

Figure 7 The effects of dopamine antagonism on stress-induced alterations in effort-based decision-making. (a) Percent choice of the HR lever after baseline or restraint stress displaying the main effect of stress, averaged across saline (Sal) and flupenthixol (Flu; $0.25 \mathrm{mg} / \mathrm{kg}$ ). Stress significantly decreased the selection of the HR options. The effect of (b) saline and (c) flupenthixol treatment, before restraint stress on effort-discounting. Rats displayed a comparable stress-induced decrease in choice of the HR lever after saline and flupenthixol treatment, relative to injection days without stress. (d) Response latencies across the four trial blocks (left) and averaged across blocks (right). Restraint stress preceded by saline injection caused a significant increase in choice latencies compared with saline alone. However, administration of flupenthixol before the stressor abolished this stress-induced increase in response latency. (e) There was no difference in the rate of lever pressing across the different experimental conditions. Stars identify significant main effect at $p<0.05$.

(f) Counterbalancing orders used for this experiment. 
In contrast to the lack of effect of DA receptor blockade on choice, flupenthixol did attenuate the effects of restraint on response latencies. Specifically, although there were no significant main effects of drug or stress (all $F s<3.68$, n.s.), the analysis did reveal a significant drug $\times$ stress $\left(F_{1,11}=5.29\right.$, $p<0.05)$ as well as a drug $\times$ stress $\times$ trial block interaction $\left(F_{3,33}=4.52, p<0.01\right)$. As shown in Figure $7 \mathrm{~d}$ (right), acute stress + saline significantly $(p<0.05)$ increased latencies to make a choice relative to saline alone. However, the stressinduced increase in response latency was abolished by pretreatment with flupenthixol, in that choice latencies after saline/stress treatment were significantly longer $(p<0.05)$ than following flupenthixol/stress. Moreover, response latencies following flupenthixol/stress did not differ from those after flupenthixol alone (which also did not differ from saline alone). Subsequent simple main effects analysis of the three-way interaction further revealed that the attenuation of stress-induced increases in response latencies by flupenthixol occurred most prominently in the last trial block (Figure 7d, left panel). Rate of lever pressing did not differ across the four treatment conditions (all $F \mathrm{~s}<1.42$, n.s.; Figure 7e). Trial omissions did not differ across treatment conditions (saline/no stress: $0.08 \pm 0.08$; saline/stress: 0.33 , \pm 0.2 ; flupenthixol/no stress: $1.08 \pm 0.6$; flupenthixol/ stress: $1.75 \pm 1.1$; all $F \mathrm{~s}<0.29$, n.s.). Collectively, the results of this experiment show that broad-spectrum blockade of DA receptors with flupenthixol before acute restraint stress (1) does not interfere with the ability of stress to disrupt effort-related choice, but (2) can mitigate the longer decision latencies induced by stress.

\section{DISCUSSION}

The main findings of this study are that decision-making involving evaluation of effort costs associated with different reward magnitudes is sensitive to acute stress. Restraint stress of $1 \mathrm{~h}$ reliably and robustly decreased preference for rats to work harder to obtain a larger reward. Acute stress also led to longer latencies to initiate a decision. These effects are not easily attributable to a reduced tolerance for delays to reward delivery, decreases in preference for larger $v s$ smaller rewards or more general disruption in motivational processes. Furthermore, stress-induced alterations in decision-making were not mimicked by the administration of exogenous CORT, suggesting that these effects do not appear to be mediated solely by increases in endogenous glucocorticoid activity. However, some (but not all) of the effects of stress appear to be mediated by increased DA activity. Administration of a DA antagonist reversed the increased choice latencies induced by restraint stress, but did not affect the decreased preference to work harder for a larger reward.

\section{Effects of Acute Stress on Choice}

In our initial experiment, we observed that $1 \mathrm{~h}$ restraint reduced preference from the high effort/HR option. In comparison, 20 min of restraint induced a slight, non-significant reduction in this preference. Other studies have shown that certain forms of memory retrieval are impaired by shorter durations of restraint (eg, 10 min; Rashidy-Pour et al, 2004).
However, the fact that we observed alterations in choice only with a longer duration of restraint suggests that dissociable forms of cognition may be differentially sensitive to the duration of an acute stressor, with decision-making processes being somewhat less sensitive to shorter duration stressors than simpler forms of learning and memory. Moreover, our results imply that the neural substrates activated by restraint stress, which may interfere with normal decision-making, may differ as a function of stress duration and corresponding neurochemical/hormonal changes.

There are a number of cognitive/motivational processes that may be disrupted by acute stress, which would in turn shift the preference away from the high effort/HR option. For example, acute stress alters metabolic processes, suppresses appetite and digestion, but also increases intake of highly palatable food (Adam and Epel, 2007). Furthermore, stress can impair spatial memory (Diamond and Rose, 1994; de Quervain et al, 1998; Kim et al, 2007), which could disrupt discrimination between the levers. Yet, it is unlikely that these explanations account for the present findings, because acute restraint stress did not affect choice on a reward magnitude discrimination task, suggesting that the effects of acute stress on effort-discounting are not due to a decrease in the subjective value of objectively larger rewards or an impairment in spatial discrimination abilities.

Choosing a higher effort option invariably delays receipt of a particular reward. Therefore, it was unclear if the effects of acute stress on effort-discounting were attributable, specifically to a reduced preference, to wait longer or work harder for the HR (or both). We assessed this possibility in two ways, the first being the use of an effort-discounting with equivalent delays procedure, which we have used previously, to dissociate between the effort and the delay components embedded within the effort-discounting task (Floresco et al, 2008b). In this procedure, delivery of the LR is comparable to the average time necessary to complete the ratio of presses on the HR lever. Thus, the relative delay cost associated with each reward is effectively equalized across options. If the effects of stress on effort-discounting were attributable primarily to a reduced tolerance for delayed rewards, then this manipulation would be expected to diminish the stress-induced effects on effort-discounting. However, this was not the case, as acute stress again shifted preference away from the high effort/HR option under these conditions.

We then investigated whether acute stress affects other forms of decision-making related to choice between smaller immediate rewards and larger delayed rewards using a delay-discounting task, a well-established means for assessing impulsive choice in rodents. In stark contrast to the effects of acute stress on effort-related decisions, similar treatments did not decrease preference for larger delayed rewards, providing further evidence that stress-induced effects on effort-based decision-making are not because of increased 'impatience' for delayed rewards. This is a key finding in that it demonstrates that acute stress does not uniformly interfere with all forms of cost/benefit decisionmaking in the same manner, and instead exerts a more selective effect on evaluations related to effort expenditures. Note that this lack of effect of acute stress on delaydiscounting contrasts with some studies with humans that have pointed to a link between stress and impulsivity 
(Giora, 1987; Wittman and Paulus, 2008; Diller et al, 2011). Differences between temporal discounting tasks used in human and animal studies may account partially for this discrepancy. Studies with humans typically give choices between hypothetical rewards delivered days-weeks after the test session, whereas rat studies require choice between rewards obtainable during the same training session. Thus, it may be that the ability of stressful events to alter sensitivity of temporal discounting may be more contingent on long-term time perception and not a general intolerance toward delays to reward.

We also investigated the possibility that acute stress may have caused a more general deficit in the motivation to work for food, or somehow interfered with the rats' ability to lever press at high ratios, using a progressive ratio schedule of reinforcement. In well-trained rats, acute stress did not alter the total number of presses, breakpoints, or rates of pressing. Similar lack of effects on progressive ratio responding have been observed after chronic mild stress (Barr and Phillips, 1998). The fact that restraint stress did not interfere with the ability to maintain responding at considerably higher ratios (as high as 77 presses) than in the effort-discounting task indicates that this manipulation does not render animals incapable of completing the required number of presses, nor it is decreasing their motivation to work for food. Thus, in the absence of a choice between different options, acute stress does not simply decrease the effort 'currency' an animal is willing to spend for a set reward. Furthermore, as restraint did not alter on progressive ratio responding or delay-discounting, this suggests that acute stress does not uniformly disrupt encoding changes of response costs. Rather, an acute stressor causes rats to choose options that require less work in exchange for less food. As such, it appears that acute stress shifts the decision criteria, whereby the relative, rather than absolute effort costs associated with larger rewards become less tolerated.

Alterations in effort-discounting induced by restraint provide novel insight into how decision-making may be influenced after acute stress. Stress has been reported to alter decision-making by increasing the likelihood of habitual behavior and impairing optimal foraging upon changes in the relative utility of different options in rats (Elliott and Packard, 2008; Graham et al, 2010) and promotes riskier, disadvantageous courses of action in humans (Miu et al, 2008; Porcelli and Delgado, 2009; Putman et al, 2010; Diller et al, 2011). The present data expand on these findings, showing that effort judgments following a stressor are biased towards the less strenuous course of action, which reduces the amount of food reward that may be obtained in the long term. However, because this alteration in decision policies would also lead to greater energy conservation, this supposed suboptimal decision-making pattern may not be completely disadvantageous. Rather, it appears that stress affects reward-related decision-making by changing response priorities, favoring those that require less energy expenditure in the pursuit of food rewards.

\section{The Effect of Stress on Decision Latencies}

In addition to altering effort-related choice, acute stress also led to longer deliberation time during effort-discounting. Similar effects of stress were observed on both the reward magnitude discrimination and the effort-discounting with equivalent delay procedure. These effects suggest that the effect of stress on choice does not appear to be the result of increased motor impulsivity, (ie, rats quickly choosing the LR option when faced with a choice). The fact that the latency effects were apparent as early as the second trial block suggest that they do not reflect some form of satietyinduced hesitation. Moreover, the lack of effect of stress on rates of lever pressing argues against the notion that stress induced a general slowing down of behavior. Additionally, the effects of stress on deliberation time and choice selection could also be dissociated, where acute restraint increased response latencies without affecting preference for the HR during the reward magnitude discrimination. Notably, choice latencies during delay-discounting were not affected by stress, although this may be because of procedural differences between the delay-discounting relative to the other tasks (eg, differences in reward magnitudes, longer intertrial intervals). Despite this one result, acute restraint did increase choice latencies in all of the other experiments of this study, suggesting that at least under some circumstances, stress increases hesitation to choose between options that differ in terms of reward magnitude and their relative effort costs.

The effects of restraint on choice latencies observed here are consistent with other reports showing increased response times following acute stress. Thermal stress has been shown to cause increases in response latencies during performance of an avoidance-escape task (Weiss and Glazer, 1975) and attack initiation (Corum and Thurmond, 1977). In these studies, animals were slower to initiate avoidance-seeking behavior, suggesting that the stress-induced increases in latency are not limited to selection-related actions. Collectively, these findings show that in addition to shifting decision biases away from larger rewards associated with a greater effort cost, hormonal/neurochemical changes occurring in response to acute stress also can make animals more 'indecisive', increasing processing times required to make these decisions.

\section{Probing Hormonal and Neurochemical Mechanisms Underlying Stress-Induced Alterations in Decision-Making}

Restraint stress triggers the release of CORT, which can contribute to alterations in cognition induced by these manipulations. To mimic this aspect of the stress response, rats were treated with CORT at doses that result in plasma levels comparable to those obtained after similar periods of restraint (Meaney et al, 1988; Imperato et al, 1991; Zhang et al, 2010; present study, Figure $6 \mathrm{c}$ and d), as well as to effectively induce corticosteroid receptor occupancy (Meaney et al, 1988) and translocation (Sarabdjitsingh et al, 2009). Treatment with $1-3 \mathrm{mg} / \mathrm{kg}$ CORT did not affect effort-related choice or other behavioral measures (rates of pressing, response latency). This lack of effect contrasts with some other findings, demonstrating that exogenous CORT treatment does alter learning and cognition in a manner similar to acute stress. Administration of CORT in rats $(1-5 \mathrm{mg} / \mathrm{kg})$ mimics the effects of acute stress on contextual fear conditioning (Cordero and Sandi, 1998) and spatial memory retrieval (de Quervain et al, 1998) by enhancing and impairing performance, respectively. In humans, 
cortisol or dexamethasone alters simple and more complex forms of cognition, such as declarative memory (Newcomer et al, 1994) and cost/benefit decision-making (Putman et al, 2010). However, other studies in rats have shown that CORT treatment does not replicate the effects of stress on place or response discrimination learning (Sadowski et al, 2009) or decision-making in response to changes in the relative utility of different reward options (Graham et al, 2010). Thus, it may be that increased CORT activity does not have as a disruptive an effect on learning or cognition in situations where animals must discriminate or choose between different options. Note that the present findings do not completely rule out the role of CORT in mediating the effects of stress on effort judgments. Changes in plasma CORT levels may interact with other stress-induced hormonal and neurochemical fluctuations to alter decision-making (eg, noradrenaline; Kukolja et al, 2008; Enkel et al, 2010). Studies using corticosteroid antagonists before stress would provide further insight into this issue. Nevertheless, these results suggest that in the absence of a physical/psychological stressor, increasing glucocorticoid levels was not sufficient to affect choice or other behavioral measures associated with effort judgments.

Another well-characterized neurochemical effect of acute stress is increased release of DA in the forebrain and mesolimbic structures (Roth et al, 1988; Abercrombie et al, 1989; Imperato et al, 1989, 1991; Davis et al, 1994; Finlay et al, 1995; Rougé-Pont et al, 1998; Tsigos and Chrousos, 2002). It has been proposed that stress-induced impairments in processes such as spatial working memory are because of excessive increases in DA release, as they are reversed by DA receptor blockade (Murphy et al, 1996a, 1996b, 1997; Arnsten and Goldman-Rakic, 1998; Arnsten et al, 2000). With respect to the present study, effort-based decision-making appears to be sensitive to DA levels, as pharmacological reductions (Salamone et al, 1991, 1997, 2003,2005 ) or enhancements in DA activity (Floresco et al, 2008b) decreases the preference to work harder for a larger reward. Therefore, we investigated whether the effects of acute stress on decision-making and related behaviors could be ameliorated by reducing DA activity.

Treatment with flupenthixol alone did not affect effortdiscounting task relative to saline. This confirms that administration of a relatively low dose $(0.25 \mathrm{mg} / \mathrm{kg})$ of this DA antagonist $80 \mathrm{~min}$ before testing does not alter choice behavior, even though higher doses of the antagonist given shortly before testing $(0.5 \mathrm{mg} / \mathrm{kg}, 20 \mathrm{~min}$ before task) does shift choice biases away from the HR option (Floresco et al, 2008b). Following restraint, rats again shifted preference away from the HR option, replicating our initial effects. However, the effect of stress on choice was not altered by the DA receptor blockade. This is in contrast with previous work demonstrating that stress-induced impairments of other forms of cognition such as working memory can be ameliorated by systemic treatment with DA antagonists (Murphy et al, 1996a, 1996b). Thus, these finding suggests that systemic, broad-spectrum blockade of DA receptors is insufficient to attenuate the effects of stress on effort-based decision biases. A parsimonious conclusion would therefore be that stress-induced increases in DA activity are not an underlying cause of alterations in choice biases during this form of decision-making. However, the possibility remains that acute stress may perturb decision-making through increases in DA transmissions in specific terminal regions, or acting on a subset of DA receptors. Alternatively, it is possible that changes in DA efflux that occur after the release from restraint may be a contributing factor to the stress-induced alterations in decision-making observed here. Future studies, using local administration of receptor-selective DA antagonists, administered either before or after stress may address these issues more completely.

In contrast to the inability of flupenthixol to reduce the effects of stress on decision-making, this treatment did counteract the effect of restraint on longer choice latencies. Thus, restraint after saline injection led to longer response latencies, replicating findings from our previous experiments. Moreover, flupenthixol by itself did not affect this measure. However, the stress-induced effect on deliberation time was reversed by pretreatment with flupenthixol, confirming that the dose used here was sufficient to reverse some of the behavioral effects of acute stress. Admittedly, this is a somewhat counterintuitive finding, given that DA antagonists typically increase response latencies. Yet, the fact that DA receptor blockade ameliorated the effects of restraint on decision latencies suggest that the ability of acute stress to increase hesitation before response selection may be mediated by increases in the DA activity.

Given that neither CORT nor DA appears to solely mediate the effects of stress on choice, the question remains regarding the hormonal and neurochemical mechanisms underlying these effects. Administration of a noradrenaline antagonist has been reported to reverse-working memory impairments induced by a pharmacological stressor, suggesting that increases in this monoamine may contribute to some of the effects reported here (Birnbaum et al, 1999). Corticotropin-releasing hormone is another transmitter that is released during stress, and post-training intra-amygdala infusions of this neuropeptide has been shown to mimic the effects of acute stress on stress-associated behaviors and avoidance learning (Liang and Lee, 1988). It is therefore possible that the effects of acute stress on effort-based decision-making may be the result of increased corticotropin-releasing hormone and noradrenaline release, although this remains to be tested experimentally.

\section{CONCLUSIONS}

In summary, these experiments suggest that acute stress interferes somewhat selectively with cost/benefit evaluations concerning rewards of different magnitudes and the relative effort costs associated with obtaining them. These effects do not appear to be attributable to increased impulsivity, or reductions in motivation to work for food rewards or for larger rewards in general, nor do they seem to be caused solely by increased CORT activity. Acute stress also induces greater hesitation to make a choice, which appears to be mediated by increased DA activity. Collectively, these studies complement a growing literature investigating how acute stress may alter different types of cognitive processes, showing here that stress may change the manner in which animals value larger rewards associated with greater effort costs. One byproduct of this effect would be to cause an organism to conserve the energy that would otherwise be 
spent on the higher effort requirement associated with the larger reward. This in turn emphasizes that the stress response would reinforce the selection of less physically demanding options, possibly in an attempt to increase energy conservation. Given that the stress response is designed to be adaptive, biasing response selection towards low-effort options may help to promote energy conservation for the time immediately following a stressor.

Negative affect and depressed mood are the most recognized phenotypes of depression. However, individuals with clinical diagnosis of depression also suffer from a number of energy-related deficiencies, such as psychomotor retardation, anergia, and fatigue (Tylee et al, 1999; Stahl, 2002). Given the intertwined relationship between stress and depression (Heit et al, 1997), this model of effort-based decision-making and its sensitivity to the acute stress may help clarify some of the underlying behavioral symptoms associated with depression. As such, this approach may not only further our understanding of the neural circuitry/ neurotransmitter systems associated with the stress-induced alterations in cost/benefit decision-making, but may also serve as a model for the anergia and motivational deficits associated with depression. This in turn may prove particularly useful in the development of novel treatments for this aspect of the disorder.

\section{ACKNOWLEDGEMENTS}

We thank Ryan Littlechilds for his excellent assistance with behavioral testing, and Dr Brenda Bingham for expert technical assistance. This research was supported by grants from the Canadian Institutes of Health Research to SBF (MOP 89861) and VV. MG is the recipient of a Canadian Graduate Student Scholarships Doctoral Award from the Canadian Institutes of Health Research. SBF and VV are both Michael Smith Foundation for Health Research Senior Scholars.

\section{DISCLOSURE}

SBF has received funds to conduct contract work for Pfizer. The work supported by this grant is not related to the findings presented in this manuscript.

\section{REFERENCES}

Abercrombie ED, Keefe KA, DiFrischia DS, Zigmond MJ (1989). Differential effect of stress on in vivo dopamine release in striatum, nucleus accumbens, and medial frontal cortex. J Neurochem 52: 1655-1658.

Adam TC, Epel ES (2007). Stress, eating and the reward system. Physiol Behav 91: 449-458.

Arnsten AF (2009). Stress signalling pathways that impair prefrontal cortex structure and function. Nat Rev Neurosci 10: 410-422.

Arnsten AFT (1998). The biology of feeling frazzled. Science 280: 1711-1712.

Arnsten AFT, Goldman-Rakic PS (1998). Noise stress impairs prefrontal cortical cognitive function in monkeys. Arch Gen Psychiatry 55: 362-368.

Arnsten AFT, Murphy B, Merchant K (2000). The selective dopamine D4 receptor antagonist, PNU101387G, prevents stress-induced cognitive deficits in monkeys. Neuropsychopharmacology 23: 405-410.

Barr AM, Phillips AG (1998). Chronic mild stress has no effect on responding by rats for sucrose under a progressive ratio schedule. Physiol and Behav 64: 591-597.

Birnbaum S, Gobeske KT, Auerback J, Taylor JR, Arnsten AFT (1999). A role of norepinephrine in stress-induced cognitive deficits: $\alpha$-1-adrenoceptro mediation in the prefrontal cortex. Biol Psychiatry 46: 1266-1274.

Broadbent D (1971). Decision and Stress. Academic: London.

Brown CM, Fletcher PJ, Coscina DV (1998). Neuropeptide Yinduced operant responding for sucrose is not mediated by dopamine. Peptides 19: 1667-1673.

Cordero MI, Sandi C (1998). A role for brain glucocorticoid receptors in contextual fear conditioning: dependence upon training intensity. Brain Res 786: 11-17.

Cordero MI, Venero C, Kruyt ND, Sandi C (2003). Prior exposure to a single stress session facilitates subsequent contextual fear conditioning in rats: evidence for a role of corticosterone. Horm Behav 44: 338-345.

Corum CR, Thurmond JB (1977). Effects of acute exposure to stress on subsequent aggression and locomotion performance. Psychosom Med 39: 436-443.

Cousins MS, Salamone JD (1994). Nucleus accumbens dopamine depletion in rats affect relative response allocation in a novel cost/benefit procedure. Pharmacol Biochem Behav 49: 85-91.

Davis M, Hitchcock JM, Bowers MB, Berridge CW, Melia KR, Roth R (1994). Stress-induced activation of prefrontal cortex dopamine turnover: blockade by lesions of the amygdala. Brain Res 664: 207-210.

de Quervain DJ, Roozendaal B, McGaugh JL (1998). Stress and glucocorticoids impair retrieval of long-term spatial memory. Nature 394: 787-790.

Diamond DM, Rose GM (1994). Stress impairs LTP and hippocampal-dependent memory. Ann NY Acad Sci 746: 411-414.

Diller JW, Patros CHG, Prentice PR (2011). Temporal discounting and heart rate reactivity to stress. Behav Processes 87: 306-309.

Elliott AE, Packard MG (2008). Intra-amygdala anxiogenic drug infusion prior to retrieval biases rats towards the use of habit memory. Neurobiol Learn Mem 90: 616-623.

Enkel T, Gholizadeh D, von Bohlen und Halback O, Sanchis-Segura C, Hurlemann R, Spangel R et al (2010). Ambiguous-cue interpretation is biased under stress- and depression-like stated in rats. Neuropsychopharmacology 35: 1008-1015.

Finlay JM, Zigmond MJ, Abercrombie ED (1995). Increased dopamine and norepinephrine release in medial prefrontal cortex induced by acute and chronic stress: effects of diazepam. Neuroscience 64: 619-628.

Floresco SB, Block AE, Tse MT (2008a). Inactivation of the medial prefrontal cortex of the rat impairs strategy set-shifting, but not reversal learning, using a novel, automated procedure. Behav Brain Res 190: 85-96.

Floresco SB, Ghods-Sharifi S (2007). Amygdala-prefrontal cortical circuitry regulates effort-based decision making. Cereb Cortex 17: $251-260$.

Floresco SB, Tse MT, Ghods-Sharifi S (2008b). Dopaminergic and glutamatergic regulation of effort- and delay-based decision making. Neuropsychopharmacology 33: 1966-1979.

Floresco SB, Whelan JM (2009). Perturbations in different forms of cost/benefit decision making induced by repeated amphetamine exposure. Psychopharmacology 205: 189-201.

Ghods-Sharifi S, Floresco SB (2010). Differential effects on effort discounting induced by inactivation of the nucleus accumbens core or shell. Behav Neurosci 124: 179-191.

Ghods-Sharifi S, St Onge JR, Floresco SB (2009). Fundamental contribution by the basolateral amygdala to different forms of decision making. J Neurosci 29: 5251-5259. 
Giora K (1987). Decision making under stress: scanning of alternatives under controllable and uncontrollable threats. J Pers Soc Psychol 52: 639-644.

Graham LK, Yoon T, Jeansok JK (2010). Stress impairs optimal behaviour in a water foraging choice task in rats. Lean Mem 17: 1-4.

Gray M, Bingham B, Viau V (2010). A comparison of two repeated restraint stress paradigms on hypothalamic-pituitaryadrenal axis habituation, gonadal status and central neuropeptide expression in adult male rats. J Neuroendocrinol 22: 92-101.

Hauber W, Sommer S (2009). Prefrontostrialtal circuitry regulates effort-related decision making. Cereb Cortex 19: 2240-2247.

Heit S, Owens MJ, Plotsky P, Nemeroff CB (1997). Corticotropinreleasing factor, stress, and depression. Neuroscientist 3: 186-194.

Imperato A, Puglisi-Allegra S, Casolini P, Angelucci L (1991). Changes in brain dopamine and acetylcholine release during and following stress are independent of the pituitary-adrenocortical axis. Brain Res 538: 111-117.

Imperato A, Puglisi-Allegra S, Casolini P, Zocchi A, Angelucci L (1989). Stress-induced enhancement of dopamine and acetylcholine release in limbic structures: role of corticosterone. Eur J Pharmacol 165: 337-338.

Inglis FM, Moghaddam B (1999). Dopaminergic innervation of the amygdala is highly responsive to stress. J Neurochem 72: $1088-1094$.

Joëls M, Pu Z, Wiegert O, Oitzl MS, Krugers HJ (2006). Learning under stress: How does it work? Trends Cogn Sci 10: 152-158.

Jorgensen A, Overo KF, Hansen V (1971). Metabolism, distribution and excretion of flupenthixol decanoate in dogs and rats. Acta Pharmacol Toxicol (Copenh) 29: 339-358.

Kant GJ, Lenox RH, Bunnell BN, Mougey EH, Pennington LL, Meyerhoff JL (1983). Comparison of stress response in male and female rats: pituitary cyclic AMP and plasma prolactin, growth hormone, and corticosterone. Psychoneuroendocrinology 8: 421-428.

Kant GJ, Leu J, Andersen S, Mougey E (1987). Effects of chronic stress on plasma corticosterone, ACTH, and prolactin. Physiol Behav 40: 775-779.

Kim JJ, Lee HJ, Welday AC, Song EY, Cho J, Sharp PE et al (2007). Stress-induced alterations in hippocampal plasticity, place cells, and spatial memory. Proc Natl Acad Sci USA 104: 18297-18302.

Kukolja J, Schlapfer TE, Keysers C, Klingmuller D, Maier W, Fink GR et al (2008). Modeling a negative response bias in the human Amygdala by noradrenergic-glucocorticoid interactions. J Neurosci 28: 12868-12876.

Liang KC, Lee EH (1988). Intra-amygdala injections of corticotrophin releasing factor facilitate inhibitory avoidance learning and reduce exploratory behavior in rats. Psychopharmacology 96: $232-236$

Luethi M, Merier B, Sandi C (2008). Stress effects on working memory, explicit memory, and implicit memory for neutral and emotional stimuli in healthy men. Frontiers in Behav Neurosci 2: $1-9$.

Meaney MJ, Viau V, Aitken DH, Bhatnagar S (1988). Stressinduced occupancy and translocation of hippocampal glucocorticoid receptors. Brain Res 445: 198-203.

Miu AC, Hellman RM, Houser D (2008). Anxiety impairs decisionmaking: psychophysiological evidence from an Iowa gambling task. Biol psychol 77: 353-358.

Murphy B, Roth R, Arnsten AFT (1997). Clozapine reverses the spatial working memory deficits induced by FG7142 in monkeys. Neuropsychopharmacology 16: 433-437.

Murphy BL, Arnsten AFT, Goldman-Rakic PS, Roth RH (1996a). Increased dopamine turnover in the prefrontal cortex impairs spatial working memory performance in rats and monkeys. Proc Natl Acad Sci USA 93: 1325-1329.
Murphy BL, Arnsten AFT, Jentsch D, Roth RH (1996b). Dopamine and spatial working memory in rats and monkeys: pharmacological reversal of stress-induced impairment. J Neurosci 1: 7768-7775.

Newcomer JW, Craft S, Hershey T, Askins K, Bardgett ME (1994). Glucocorticoid-induced impairment in declarative memory performance in adult humans. J Neurosci 14: 2047-2053.

Porcelli AJ, Delgado MR (2009). Acute stress modulates risk taking in financial decision making. Psychol Sci 20: 278-283.

Putman P, Antypa N, Crysovergi P, van der Does WAJ (2010). Exogenous cortisol acutely influences motivated decision making in healthy young men. Psychopharmacology 208: 257-263.

Rashidy-Pour A, Sadeghi H, Taherain AA, Vafaei AA, Fathollahi Y (2004). The effects of acute restraint stress and dexamethasone on retrieval of long-term memory in rats: an interaction with opiate system. Behav Brain Res 154: 193-198.

Roth RH, Tam S, Ida Y, Yang JX, Deutch AY (1988). Stress and the mesocorticolimbic dopamine system. Ann NY Acad Sci 537: 138-147.

Rougé-Pont F, Deroche V, Le Moal M, Piazza PV (1998). Individual differences in stress-induced dopamine release in the nucleus accumbens are influenced by corticosterone. Eur J Neurosci 10: 3903-3907.

Sadowski RN, Jackson GR, Wieczorek L, Gold PE (2009). Effects of stress, corticosterone, and epinephrine administration on learning in place and response tasks. Behav Brain Res 205: 19-25.

Salamone JD, Correa M, Mingote S, Weber SM (2003). Nucleus accumbens dopamine and the regulation of effort in foodseeking behavior: implications for studies of natural motivation, psychiatry, and drug abuse. J Pharmacol Exp Ther 305: 1-8.

Salamone JD, Correa M, Mingote S, Weber S (2005). Beyond the reward hypothesis: alternative functions of nucleus accumbens dopamine. Curr Opin Pharmacol 5: 34-41.

Salamone JD, Cousins MS, Snyder BJ (1997). Behavioral functions of nucleus accumbens dopamine: Empirical and conceptual problems with the anhedonia hypothesis. Neurosci Biobehav Rev 21: 341-359.

Salamone JD, Steinpreis RE, McCullough LD, Smith P, Grebel D, Mahan K (1991). Haloperidol and nucleus accumbens dopamine depletion suppress lever pressing for food but increase free food consumption in a novel food choice procedure. Psychopharmacology 104: 15-521.

Sarabdjitsingh RA, Meijer OC, Schaaf MJ, de Kloet ER (2009). Subregion-specific differences in translocation patterns of mineralocorticoid and glucocorticoid receptors in rat hippocampus. Brain Res 1249: 43-53.

Schweimer J, Hauber W (2005). Involvement of the rat anterior cingulate cortex in control of instrumental responses guided by reward expectancy. Learning Mem 12: 334-342.

Schweimer J, Hauber W (2006). Dopamine D1 receptors in the anterior cingulate cortex regulate effort-based decision making. Learn Mem 13: 777-782.

Shansky RM, Rubinow K, Brennan A, Arnsten AFT (2006). The effects of sex and hormonal status on restraint-stress-induced working memory impairment. Behav Brain Funct 2: 8.

Shors TJ, Weiss C, Thompson RF (1992). Stress-induced facilitation of classical conditioning. Science 257: 537-539.

Stahl SM (2002). The psychopharmacology of energy and fatigue. J Clin Psychiatry 63: 7-8.

Stillman MJ, Shukitt-Hale B, Levy A, Lieberman R (1998). Spatial memory under acute cold and restraint stress. Physiol Behav 64: 605-609.

St Onge JR, Floresco SB (2009). Dopaminergic modulation of riskbased decision making. Neuropsychopharmacology 34: 681-697.

Tsigos C, Chrousos GP (2002). Hypothalamic-pituitary-adrenal axis, neuroendocrine factors and stress. J Psychosom Res 53: 865-871. 
Tylee A, Gastpar M, Lepine JP, Mendlewicz J (1999). DEPRES II (Depression Research in European Society II): a patient survey of the symptoms, disability and current management of depression in the community. Int Clin Psychopharmacol 14: 139-151.

Walton ME, Bannerman DM, Alterescu KM, Rushworth MFS (2003). Functional specialization within medial frontal cortex of the anterior cingulate for evaluating effort-related decisions. J Neurosci 23: 6475-6479.

Walton ME, Bannerman DM, Rushworth MFS (2002). The role of rat medial frontal cortex in effort-based decision making. J Neurosci 15: 10996-11003.

Weiss JM, Glazer HI (1975). Effects of acute exposure to stressors on subsequent avoidance-escape behavior. Psychosom Med 37: 499-521.
Williamson M, Bingham B, Viau V (2005). Central organization of androgen-sensitive pathways to the hypothalamic-pituitaryadrenal axis: implications for individual differences in responses to homeostatic threat and predisposition to disease. Prog Neuropsychopharmacol Biol Psychiatry 29: 1239-1248.

Wittman M, Paulus MP (2008). Decision making, impulsivity and time perception. Trends Cogn Sci 12: 7-12.

Zeeb FD, Floresco SB, Winstanley CA (2010). Contribution of the orbitofrontal cortex to impulsive choice: interaction with basal levels of impulsivity, dopamine signaling, and reward related cues. Psychopharmacology 211: 87-98.

Zhang R, Jankord R, Flak JN, Solomon MB, D'Alessio DA, Herman JP (2010). Role of glucocorticoids in tuning hindbrain stress integration. J Neurosci 30: 14907-14914.

Supplementary Information accompanies the paper on the Neuropsychopharmacology website (http://www.nature.com/npp) 